\title{
Experimental Investigation of Indirect Solar Cooker using Evacuated Tube Collector with Dual Thermal Storage Unit
}

\author{
Munish Gupta', Sunil Kumar ${ }^{*}$ and Puneet Katyal ${ }^{\dagger}$ \\ †Department of Mechanical Engineering, Guru Jambheshwar University of Science \& Technology, Hisar (India)-125001, India
}

Accepted 25 July 2015, Available online 01 Sept 2015, Vol.5, No.3 (Sept 2015)

\begin{abstract}
In this article, an indirect solar cooker using evacuated tube collector and dual sensible thermal storage unit with copper pipe is investigated experimentally. The main aspect of this solar cooker is that its thermal storage unit is made from cheap and locally available materials sand and iron grits. The water (heat transfer fluid) which gets heated in the evacuated tube is used for indirect cooking with the help of sand and iron grit. The sand and iron grit takes heat from water and this heat is used for cooking. The hot water flows in upwards direction because of thermosyphon phenomena. It was found that this type of solar cooker can cook different kinds of food for afternoon and evening cooking. It is also helpful for keep food warm till late night hours. The payback period of this solar cooker when compared with LPG and Electricity is 8.88 and 7.61 months respectively.
\end{abstract}

Keywords: Solar Cooker, Thermal storage unit, Evacuated tube collector, heat transfer fluid, water, sand, iron grits, cooking power.

\section{Nomenclature}

\begin{tabular}{ll}
\hline \multicolumn{2}{l}{ Subscripts } \\
\hline $\mathrm{M}_{\text {sand }}$ & Mass of Sand $(\mathrm{Kg})$ \\
$\mathrm{C}_{\text {sand }}$ & Specific heat of Sand $\left(\mathrm{KJ} / \mathrm{Kg} /{ }^{\circ} \mathrm{C}\right)$ \\
$\mathrm{M}_{\text {iron grit }}$ & Mass of iron grits $(\mathrm{Kg})$ \\
$\mathrm{C}_{\text {iron grit }}$ & Specific heat of iron grits $\left(\mathrm{KJ} / \mathrm{Kg} /{ }^{\circ} \mathrm{C}\right)$ \\
$\mathrm{M}_{\mathrm{c}}$ & Mass of container $(\mathrm{Kg})$ \\
$\mathrm{I}_{\mathrm{a}}$ & Average intensity of solar radiations $\left(\mathrm{w} / \mathrm{m}^{2}\right)$ \\
$\mathrm{A}$ & Area of collector $\left(\mathrm{m}^{2}\right)$ \\
$\mathrm{M}_{\mathrm{w}}$ & Mass of cooking medium $(\mathrm{Kg})$ \\
$\mathrm{C}_{\mathrm{w}}$ & Specific heat of cooking medium, water \\
& (KJ/Kg/ $\left./{ }^{\circ} \mathrm{C}\right)$ \\
$\tau$ & Time $(\mathrm{s})$ \\
$\mathrm{T}_{\mathrm{s}}$ & Temperature of Sand in ${ }^{\circ} \mathrm{C}$ \\
$\mathrm{T}_{\mathrm{ig}}$ & Temperature of Iron grits in ${ }^{\circ} \mathrm{C}$ \\
$\mathrm{T}_{\mathrm{a}}$ & Ambient temperature in ${ }^{\circ} \mathrm{C}$ \\
$\mathrm{T}_{1}$ & Temperature of cooking medium in cooking \\
& pot 1 in ${ }^{\circ} \mathrm{C}$ \\
$\mathrm{T}_{2}$ & Temperature of cooking medium in cooking \\
& pot 2 in ${ }^{\circ} \mathrm{C}$ \\
$\mathrm{T}_{\mathrm{i}}$ & Temperature of water at inlet of header in ${ }^{\circ} \mathrm{C}$ \\
$\mathrm{T}_{\mathrm{o}}$ & Temperature of water at outlet of header ${ }^{\circ} \mathrm{C}$ \\
$\mathrm{I}$ & Intensity of solar radiation $\left(\mathrm{W} / \mathrm{m}{ }^{2}\right)$ \\
&
\end{tabular}

\section{Introduction}

Solar cooking is considered as a simple, the most viable and attractive options in terms of the utilization of

*Corresponding author: Sunil Kumar

DOI: http://dx.doi.org/10.14741/ijtt/22774114/5.3.2015.1 solar energy. Energy is a form of power that is used to do many works. We use energy to light our houses, to run various means of transportation such as trains, planes, ships, rockets etc. Energy warms our homes, cooks our food, plays our music, runs computer, allows us to see images on the TV screen and do many more things. Energy is what makes the world go around.

It is what makes this world of ours work. Animal eat food and convert it to energy using complex biochemical process. This energy is then utilized in the form of work or exercise however plants are actual converter of solar Energy into biomass. Solar energy is referred to as the energy that comes from the sun's rays incident per unit area on the surface of Earth. There are several ways of utilizing this power however use of solar power in present time is mainly restricted to generate electricity, desalination of seawater, solar cooking, solar water heating and space program.

Solar energy has always been widely available on Earth since times immemorial; plants have been efficient natural trapper of this energy since their origin on Earth while humanity has made remarkable progress in harnessing this form energy in the last few decades. Fossil fuel based energy resources still predominate with the highest share in global energy consumption. The energy required for cooking is supplied by non-commercial fuels like coal, agricultural waste, dung and oil. In India, energy demand for cooking accounts for $36 \%$ of total primary energy consumption (Saxena A et al, 2011). People in rural 
areas have no choices but to walk several kilometers every day to collect firewood. Besides the environmental and economic burden of noncommercial fuels, there are some serious health problems such as burns, eye disorder and lung diseases originate from the utilization of firewood. Therefore this situation requires more attention towards renewable energy substitutions to meet the cooking requirements of people in developing countries.

In recent year's lot of research have done on solar cooker incorporating thermal storage material. Researchers used different types of solar cooker for conducting experiments to improve shortcomings of solar cookers. In general lot of work has been done on solar cooker incorporating phase change material and lot of work has to be done in coming future. List of work done on solar cooker are:

Ramadan et al. developed a solar cooker by storing solar energy in sand in the form of specific heat. They used sand because of its high heat retention capability but it requires large volume to deal with. They used sand because of its low cost, easy availability. By using sand; cooker performance increased during the daytime and about 3hrs/day of indoor cooking was possible. It can also keep the food warm during night time as oven do.

Al-saad et al. experimentally investigated a solar cooker, made from clay that is easily available and of low cost. The main characteristics that distinguish this type of solar cooker from others, is made from locally available materials, economical feasible and no extra skilled labour required to design the solar cooker. In this setup, they use the black stone pebbles for storing solar energy instead of absorbing plate. The use of black stone instead of absorber plate makes more efficient solar cooker that is capable of storing more solar energy, results in late time cooking and more effective than any other type of conventional solar cooker.

Domanski et al. studied solar cooker experimentally for cooking at sunshine and off-sunshine hours by the use of phase change materials (PCMs) as storage medium. For this purpose, they designed two concentric cylindrical vessels and $2 \mathrm{~cm}$ gap is provided between them to keep phase change material (PCM). This gap was filled with the PCMs as magnesium nitrate hexahydrate (MNHH) and stearic acid (SA). The cooker performance is calculated in terms of charging and discharging times of the PCMs. They found that overall efficiency of the solar cooker during discharging is to be 3-4 times greater than that for steam and heat pipe solar cookers, which can be used for indoor cooking. During solidification of $\mathrm{MNHH}$, temperature of cooking food in the range $78-84^{\circ} \mathrm{C}$ is to be found which is higher than the required lowest temperature. The solar cooker is tested under different climatic conditions.

Buddhi et al. experimentally studied and fabricated a solar cooker of box type with latent heat storage unit for late night cooking. They used Commercial grade
PCM Stearic acid for storing solar energy as storage medium. They cooked different kinds of food for different duration of time, several times in a day and it was found that the temperature of the plate is $65^{\circ} \mathrm{C}$ at 8:00 PM which shows that the food can be hot for next two hours at late night. The experimental result shows that the food can be cooked even in the evening with this type of solar cooker. Then the experimental results are compared with conventional type of solar cooker.

Funk et al. studied solar cooker and presents a model for prediction of the cooking power which was based on mainly three controlled parameters such as solar intercept area, over all heat loss coefficient, thermal conductivity of absorbing plate and three controlled variables such as insolation falling on the area, the load distribution and the temperature difference. They determined the fundamental energy balance equation and coefficient for each term in the model by regression analysis of the experimental data.

Gaur et al. experimentally investigated the performance of solar cooker, special emphasis on the shape of lid of the utensils that was used for improving the cooking performance of solar cooker for cooking food. This study concludes that solar cooker performance can be improvised by using a concave shape lid rather than plain lid utensils. Thereafter they compare the results with normal lid utensils and found that stagnation temperature for a utensil having a concave lid was about $2-7 \%$ more than the utensil with a normal lid. They performed water heating test which showed that utensil have a concave shape lid took about $10-13 \%$ less time than the time taken by utensils with a normal lid for the same temperature rise of water in both the utensils.

Sharma et al. developed a solar cooker for cooking food in the evening and night time also. They used PCM storage unit to store solar energy during sunshine hours. The energy stored by PCM was used to cook food in the evening and during off sun-shine hours also. Commercial grade PCM acetamide was used as a latent heat storage material for storing solar energy from the sun. From the experimental results, they conclude that the storage of the solar energy does not affect the performance of the solar cooker for noon cooking and PCM should have melting temperature between 105 to $110^{\circ} \mathrm{C}$, more suitable for cooking food with the present design during the evening and late night hours also.

Buddhi et al. developed experimental setup in new way by the use of three reflectors and evaluated thermal performance of solar box cooker with latent heat storage unit for evening cooking. They use phase change material for storing energy. Commercial grade PCM acetanilide was used which stored energy during day time and sun-shine hours.

They conducted cooking experiments with different loads and loading times during the winter season at evening time and late night hours also. They concluded that box type solar cooker with three reflectors that was used to enhance the incident solar radiation for 
improving the performance of solar cooker was successful and also able to cook food during the evening and night hours also.

Schwarzer et al. design and developed an indirect solar cooking system with or without temporary heat storage for cooking food during day and off sunshine hours also. They investigate the solar cooker and results the possibility of indoor cooking and night cooking by using vegetable oil as the heat transfer fluid. The heat transfer fluid i.e. vegetable oil that is heated up in the collector and moves by natural circulation without any extra work to the cooking unit, where it transfer parts of its sensible energy to the cooking goods in double walled pots. During charging phase, the solar energy absorbed by the working fluid and gets heated and then stored in the oil-pebble tank. The plot shows temperature measurements and variation at different times and at different load at the outside walls of the container at loading and unloading times. During discharging phase, when cooking is done after sunset, the heat released by the storage unit is calculated by sensible water heating test that shows the sensible heat gain by water with respect to time.

Subodh Kumar studied the box type solar cooker, thermal performance and study of top heat losses coefficient that constitute the major losses and has a strong influence on the thermal performance of cooker. They performed several outdoor and indoor experiments to develop a correlation for the variable $\mathrm{U}_{\mathrm{tw}}$ of as a function of pot water temperature, wind speed and ambient air temperature. Their investigation reveals that the time for cooking or heating water at certain temperature depends on solar radiation level and type and quantity of load.

Harmim et al. designed, developed and investigated the thermal performance of two identical box cooker experimentally. One type of solar cooker having conventional plate for absorbing sunlight and another type of solar cooker have absorbing plate with fins. After conducting experiments and several studies they found that the finned absorber plate results in achieving higher performance by reducing the cooking time by $12 \%$ as compared then the ordinary type of solar cooker. The stagnation temperature of box type solar cooker equipped with finned absorber plate was found to be $7 \%$ more than the ordinary cooker.

Harmim et al. constructed and evaluated the performance of box type solar cooker employing an asymmetric compound parabolic concentrator. The cooker performance studied and it is found that cooker can be cooked two meals per day for a family of four persons. During no- load conditions, the maximum temperature attained by absorbing plate are $166^{\circ} \mathrm{C}$ and $165^{\circ} \mathrm{C}$ in hot and cold season respectively. This cooker needs no tracking with time. This is the advantage of this type of cooker.

Sethi et al. presents box type solar cooker with parallelepiped cooking vessel design for improving cooker performance especially in winter conditions. Solar cooker is optimally inclined for capturing solar radiation effectively. The cooking performance parameters of proposed inclined cooker coupled with new vessel design are compared with horizontally placed inclined cooker of same material and dimensions coupled with conventional cylindrical vessel design. Time taken to boil water and cooking power was $37 \%$ less and $40 \%$ more respectively in parallelepiped shaped cooking vessel of inclined cooker as compared to conventional cylindrical vessel of horizontally placed cooker.

Sharma et al. summarized the work done on solar cooking system with phase change material for cooking at evening and late night hours. Phase change materials store energy during sun shine hours (charging time) and release their latent heat during discharging time which can be used during evening and off sun-shine hours for cooking food. Their work is mainly focused on the thermal energy storage solar technology for solar cooker. Thermal storage unit provides facility of cooking food at night also.

Muthusivagami et al. studied all the research wok and developments done on solar cooker for improving solar cooker efficiency with and without thermal energy storage. They also discussed the new design of solar cooker incorporating phase change material having evacuated tube solar collector. They studied the work done on box type solar cooker, parabolic dish type and flat plate collector with and without thermal storage for getting effective results during cooking and for long time also till late night.

Saxena et al. reviewed the literature of solar box cooker and suggested reforms in the existing design of solar cookers. Focus of their study on different components of solar cooker which are affecting the performance, working, economic aspects of cooker. They also designed a box type solar cooker with wiper mechanism for removing vapor droplets from the bottom of the glazing during the cooking time. The wiper mechanism added in the design is helpful in reducing the cooking time and efficiently cook the food.

Umanand et al. modeled and designed a hybrid solar cooking unit. This cooking unit consists of parabolic trough collector, thermal storage tank, heat exchanger respectively. The heat was supplied by heat transfer fluid (servo-thermo oil) to the thermal storage unit by natural convection process. In this system supply of energy was two way, firstly energy supplied by the oil to the cooking pot and secondly energy supplied by LPG. This system provides the facility of using LPG and solar energy according to the situation. The hybrid cooking unit was very useful and had great advantage. The performance of this cooking unit was controlled by varying the fluid flow rate from collector to thermal storage unit and from thermal storage unit to the heat exchanger. The performance of this unit also depends on the diameter of pipes containing heat transfer fluid. The whole system was modeled with the help of bond graph approach.

Panwar et al. reviewed on standard testing approach for box type and parabolic type solar cooker. 
They evaluate the energy and exergy efficiency of concentrating type solar cooker. They also analyze their thermal performance and economic aspect and other affecting factors for solar cookers in both laboratory and actual conditions.

Mussard et al. presents a solar cooker with thermal storage unit, for high temperature, charging and simulation. A self- circulating loop is coupled with heat storage and a parabolic trough for charging experiments. The whole cooking system is filled with thermal oil (Duratherm 630). The parabolic trough focuses the energy on a tube absorber. The storage is originally based on aluminium cylinders filled with nitrate salts immersed in the heated oil coming from the self-circulating loop. The salt provides latent heat to the heat storage (melting temperature: 215 to $225^{\circ} \mathrm{C}$ ).

Mussard et al. developed a low cost small scale parabolic trough coupled with heat storage unit for cooking purposes at higher temperature. They compare the results with insulated absorbing tube and without insulating absorbing tube during conducting experiment. Thermal oil (Duraetherm 630) is used as a self-circulating fluid in the system. The storage is mainly based on oil but have a part of nitrate salts to store energy. There are eight aluminium hollow cylinders in which salts are provided. A plate is attached on the top of cylinders and the whole assembly is immersed into a container where the hot oil flows. The result concludes that absorber without insulation is more effective in low temperature conditions also.

Saini et al. investigates and studied the performance of solar cooker for sun shine and off sunshine hour cooking. They use parabolic trough collector having aperture area $1.4 \mathrm{~m}^{2}$ with thermal storage unit for off sun-shine hour cooking. They use the PCM acetenalide (commercial grade) having melting temperature $118.9^{\circ} \mathrm{C}$. They conclude that system can be cooked two times in a day. They use thermal oil as a heat transfer fluid and found that rate of evening cooking is 1.6 to 3 times faster as compared to noon cooking.

Many researchers have worked on solar cooker based on box type, parabolic dish and parabolic trough type solar collector, flat plate collector with thermal storage unit but very few researcher groups have worked on evacuated tube collector coupled with thermal storage unit. To the best of author's knowledge no work has been performed using evacuated tube collector with dual sensible thermal storage unit with copper pipe (which is inserted in TSU) for cooking during day and off-sun shine hours.

\section{Description of the solar cooking system}

In order to investigate the feasibility of afternoon and evening indoor cooking with the help of solar energy stored by TSU in the form of thermal energy, the experimental setup is designed and fabricated as shown in Fig.1. The experimental setup consists several components such as evacuated tube collector (ETC),thermal storage unit (TSU) containing sand and iron grit as heat storage material, Water as a heat transfer fluid, Copper pipe, Ball valve, Reflector, wooden box having glass wool for insulaton. The evacuated tube collector has an area of $0.809 \mathrm{~m}^{2}$ made of 10 numbers of evacuated tubes which is responsible for absorbing sunlight and convert the available cold water into usable hot water. The inner tube has a solar absorbing coating of Al-SS-Cu alloy and the vacuum is provided between them. The space between adjacent tubes is $0.042 \mathrm{~m}$. The evacuated tubes are made from borosilicate ensuring excellent strength and resilience. The evacuated glass tube design specification is given in table 1.A header section is provided with the tubes for collecting water. It is made up of mild steel having ten holes on the lateral surface of square pipe having area $1 \mathrm{~m}^{2}$. One end of the evacuated tubes is placed in these holes and the closed ends are supported by the frame. On outer surface of the square pipe, an insulation of glass wool is used to prevent the heat loss from the header to the atmosphere. The header is filled with water as heat transfer fluid. One end of the header is connected to the inlet to solar cooker and other is connected to the outlet of the solar cooker. An thermal storage unit consisting of sand and iron grits is connected with the evacuated tube solar collector for storing energy during sunshine hours and provide this energy during off sunshine hours. Thermal storage unit consists $10 \mathrm{Kg}$ of iron grits and $5 \mathrm{~kg}$ of sand. This unit consists of two rectangular vessels having void space in between them, which is filled by these energy storage materials. Copper tubes are wounded around to the outer surface of middle vessel for enhancing heat transfer rate as shown in figure 2. The design specifications of TSU and copper pipes wounded outside of the middle container are listed in Table 2. The selection of these energy storage materials in solar cooking is based upon the facts that these materials are readily available and further no chemical storage of energy take place eliminating the phobia of contamination of food as in case of storage of thermal energy by using chemical means in Solar cooking. Thermo-physical properties of sand, iron grits and water are shown in table 3.

Two cylindrical shape aluminium cooking pots having 2.5 liter capacity each is inserted in the TSU for cooking. In this experimental setup, heat transfer fluid (water) is used for transferring heat from one place to other place. Water is filled in the whole circuit including evacuated tubes, header, connecting pipes, and copper pipe wounded outside of the middle container. It acts as a medium which transfer heat from collector header to the cooker. Ball valves are provided at the inlet and exit of the solar cooker to control the flow of hot water from the evacuated tube collector to the solar cooker. A reflector is used beneath the evacuated tubes to reflect the sunlight on the evacuated tubes. Insulation is provided to prevent the heat loss from the thermal storage unit. 
Table 1: Vacuum Glass Tube design Specification

\begin{tabular}{|c|c|}
\hline \multicolumn{2}{|c|}{ Tube specification } \\
\hline Tube outer diameter & $0.058 \mathrm{~m}$ \\
\hline Tube inner diameter & $0.047 \mathrm{~m}$ \\
\hline Tube length & $1.8 \mathrm{~m}$ \\
\hline Heat loss & $<0.6 \mathrm{w} / \mathrm{sq} \mathrm{m}$ \\
\hline Thickness of glass & $0.0016 \mathrm{~m}$ \\
\hline Material & Borosilicate 3.3 glass \\
\hline Absorptive Coating & AL-SS/CU (Three Target) \\
\hline Absorptance & $>94 \%$ \\
\hline
\end{tabular}

Table 2: Design Specifications of Thermal Storage Unit (TSU) and Copper pipe

\begin{tabular}{|c|c|}
\hline \multicolumn{2}{|c|}{ Thermal storage unit } \\
\hline Length of external vessel & $0.56 \mathrm{~m}$ \\
\hline Width of external vessel & $0.28 \mathrm{~m}$ \\
\hline Height of external vessel & $0.20 \mathrm{~m}$ \\
\hline Length of internal vessel & $0.45 \mathrm{~m}$ \\
\hline Width of internal vessel & $0.19 \mathrm{~m}$ \\
\hline \multicolumn{2}{|c|}{ Copper Pipe } \\
\hline Number of rounds & 4 \\
\hline Diameter of tube & $0.125 \mathrm{~m}$ \\
\hline Length of tube & $6.09 \mathrm{~m}$ \\
\hline
\end{tabular}

Table 3: Thermophysical properties of Sand, Iron grits and Water

\begin{tabular}{|c|c|c|c|}
\hline Properties & Sand & Iron grit & Water \\
\hline Density $\left(\mathrm{Kg} / \mathrm{m}^{3}\right)$ & 1700 & 6800 & 1000 \\
\hline Specific heat $(\mathrm{KJ} / \mathrm{Kg}-\mathrm{k})$ & 0.8 & 0.48 & 4.186 \\
\hline Thermal conductivity(W/m-k) & 0.3075 & 55 & - \\
\hline
\end{tabular}

Table 4: Values of performance parameters for Indoor Morning and Evening cooking Session

\begin{tabular}{|c|c|c|c|c|}
\hline \multirow{2}{*}{} & \multicolumn{2}{|c|}{ Indoor cooking } & \multicolumn{2}{c|}{ Indoor cooking } \\
\cline { 2 - 5 } & $\begin{array}{c}\text { Morning } \\
\text { session } \\
\text { (Water) }\end{array}$ & $\begin{array}{c}\text { Evening } \\
\text { session } \\
\text { (Water) }\end{array}$ & $\begin{array}{c}\text { Morning session } \\
\text { (Rice+ water) and ( } \\
\text { Pulse+ water) }\end{array}$ & $\begin{array}{c}\text { Evening session } \\
\text { (Rice+ water) and ( } \\
\text { Pulse+ water) }\end{array}$ \\
\cline { 2 - 5 } & $\mathbf{2 1 - 0 5 - 2 0 1 5}$ & $\mathbf{2 1 - 0 5 - 2 0 1 5}$ & $\mathbf{2 2 - 0 5 - 2 0 1 5}$ & $\mathbf{2 2 - 0 5 - 2 0 1 5}$ \\
\hline $\mathbf{Q}_{\text {TsU }}$ & $289.44 \mathrm{KJ}$ & $229.20 \mathrm{KJ}$ & $298.88 \mathrm{KJ}$ & $245.52 \mathrm{KJ}$ \\
\hline $\mathbf{Q}_{\mathbf{W}}$ & $20.1 \mathrm{~W}$ & $21.22 \mathrm{~W}$ & $20.75 \mathrm{~W}$ & $22.73 \mathrm{~W}$ \\
\hline $\mathbf{P}_{\mathbf{H}}$ & $33.64 \mathrm{~W}$ & $49.88 \mathrm{~W}$ & $35.53 \mathrm{~W}$ & $51.55 \mathrm{~W}$ \\
\hline
\end{tabular}

Table 5: Cost estimation of Solar cooker with thermal storage unit

\begin{tabular}{|c|c|}
\hline Components & Cost (Rs.) \\
\hline Evacuated tube collector & 5000 \\
\hline Cooking pot \& TSU & 2000 \\
\hline Black Paint & 100 \\
\hline Iron grit & 100 \\
\hline Sand & 100 \\
\hline Insulator Box & 500 \\
\hline Reflector & 200 \\
\hline Total Cost & $\mathbf{8 0 0 0}$ \\
\hline
\end{tabular}


Table 6: Uncertainty analysis of measured data

\begin{tabular}{|c|c|c|c|c|}
\hline Name of Instrument & Variable measured & $\begin{array}{c}\text { Least division of } \\
\text { measuring } \\
\text { instrument }\end{array}$ & $\begin{array}{c}\text { Max. values } \\
\text { measured in } \\
\text { experiment }\end{array}$ & $\begin{array}{c}\text { Uncertainty } \\
\%\end{array}$ \\
\hline Thermocouple & Water temperature at inlet of & $1^{\circ} \mathrm{C}$ & $92.8^{\circ} \mathrm{C}$ & 1.07 \\
\hline header & $1^{\circ} \mathrm{C}$ & $94.5^{\circ} \mathrm{C}$ & 1.05 \\
\hline Thermocouple & Water temperature at outlet \\
of header & $1^{\circ} \mathrm{C}$ & $70^{\circ} \mathrm{C}$ & 1.42 \\
\hline Thermocouple & $\begin{array}{c}\text { Iron grits temperature } \\
\text { Sand temperature }\end{array}$ & $1^{\circ} \mathrm{C}$ & $69^{\circ} \mathrm{C}$ & 1.44 \\
\hline Thermocouple & Ambient temperature & $1^{\circ} \mathrm{C}$ & $44^{\circ} \mathrm{C}$ & 2.27 \\
\hline Solar power meter & Intensity of solar radiations & $10 \mathrm{~W} / \mathrm{m}^{2}$ & $1378 \mathrm{~W} / \mathrm{m}^{2}$ & 0.72 \\
\hline
\end{tabular}
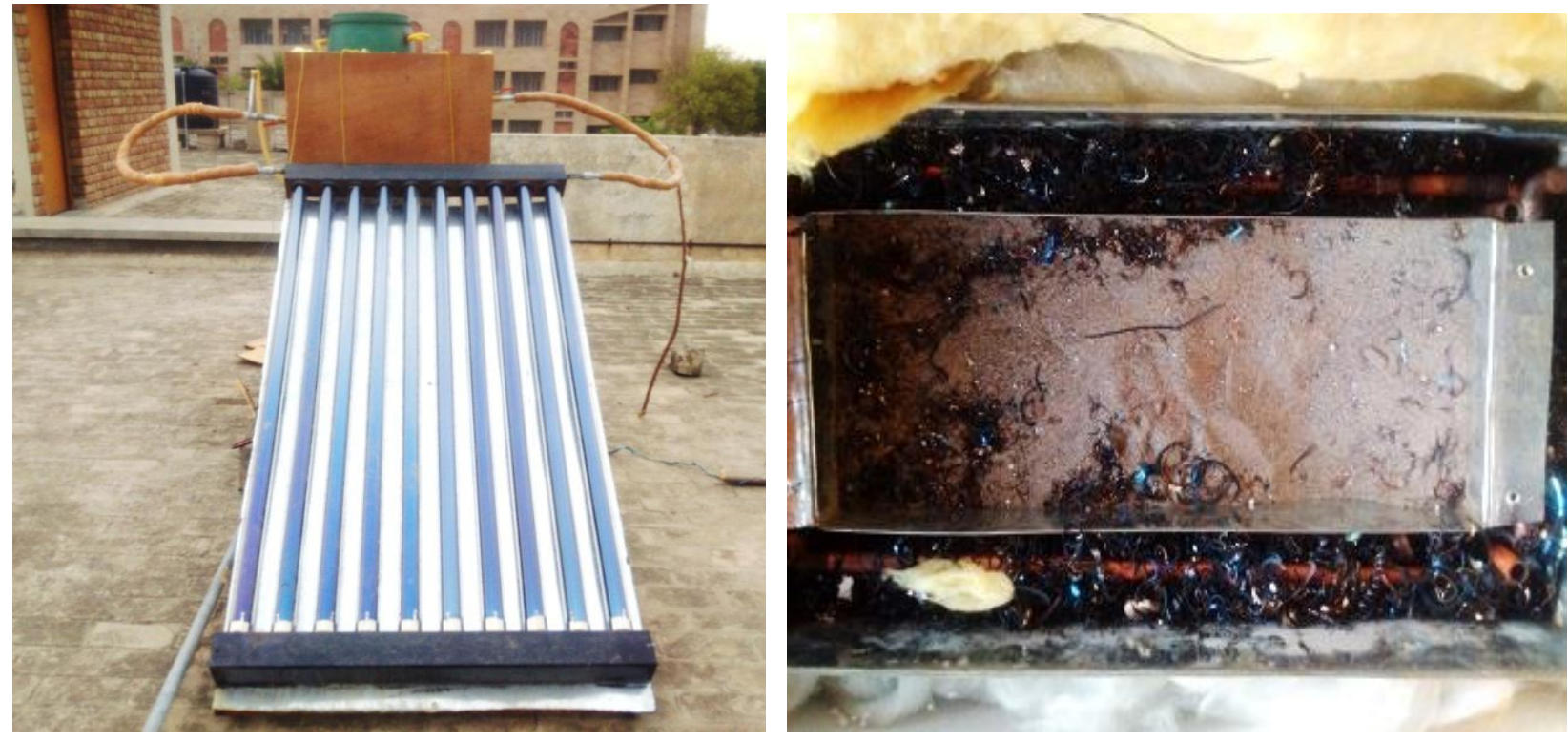

Fig. 1: Photograph of Experimental setup

Fig.2: Photograph of Thermal Storage Unit (TSU)

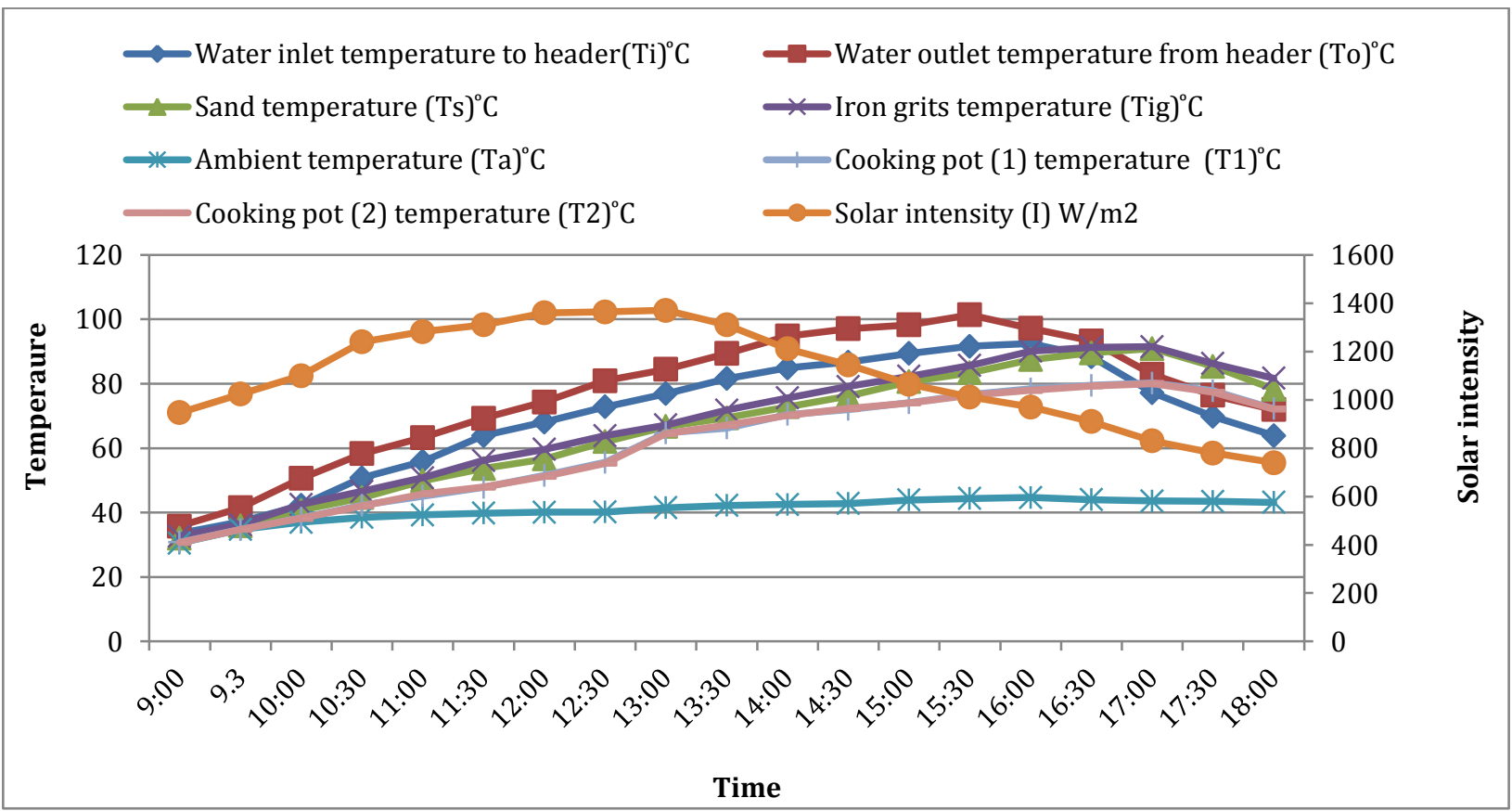

Fig. 3: Variation of temperature and Solar radiation intensity of Solar Cooker without cooking load, 20 May 2015 
Water inlet temperature to header(Ti) ${ }^{\circ} \mathrm{C}$

- Sand temperature $(\mathrm{Ts})^{\circ} \mathrm{C}$

$\because$ Ambient temperature $(\mathrm{Ta})^{\circ} \mathrm{C}$

Cooking pot (2) temperature $(\mathrm{T} 2)^{\circ} \mathrm{C}$
Water outlet temperature from header $(\mathrm{To})^{\circ} \mathrm{C}$

$*$ Iron grits temperature $(\mathrm{Tig})^{\circ} \mathrm{C}$

$\longrightarrow$ Cooking pot (1) temperature (T1) ${ }^{\circ} \mathrm{C}$

- Solar intensity (I) W/m2

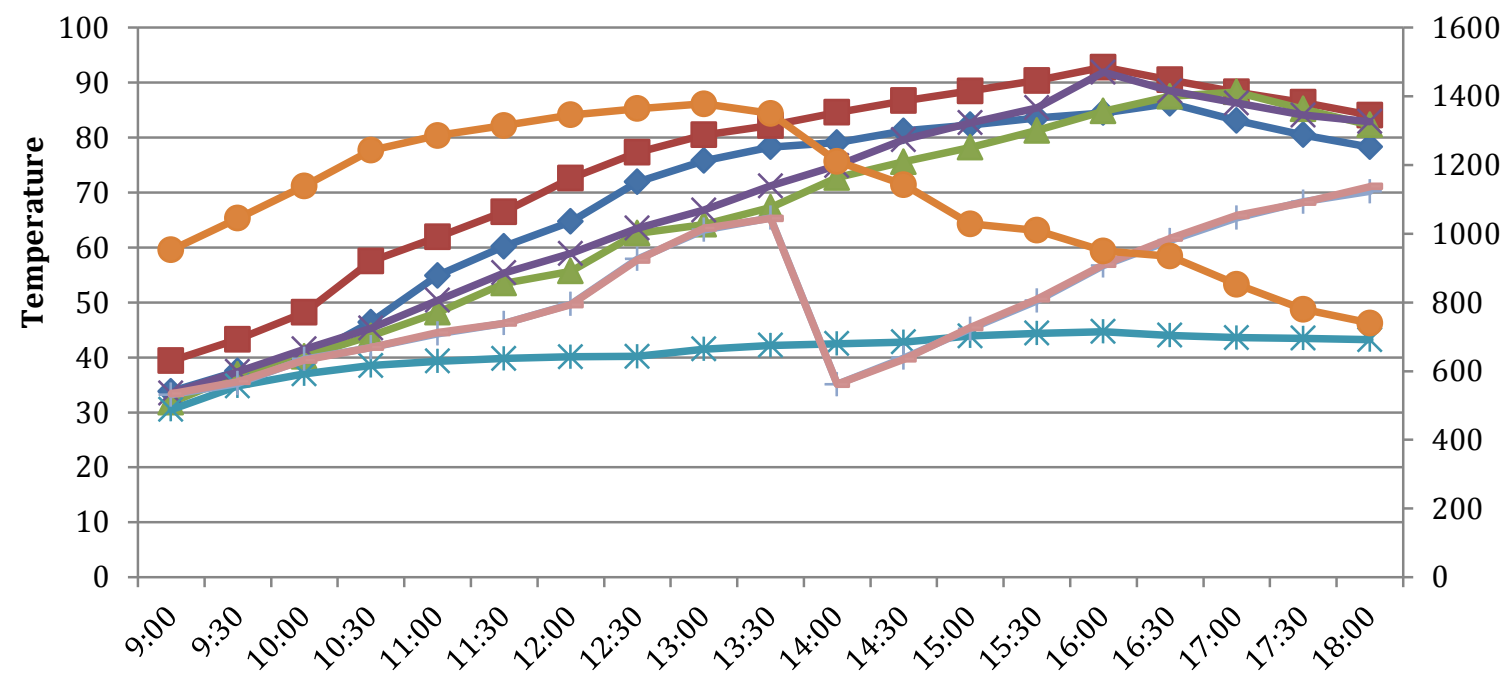

Time

Fig. 4: Variation of Temperature and Solar radiation intensity of Solar Cooker with 1ltr water as a cooking load, 21 May 2015

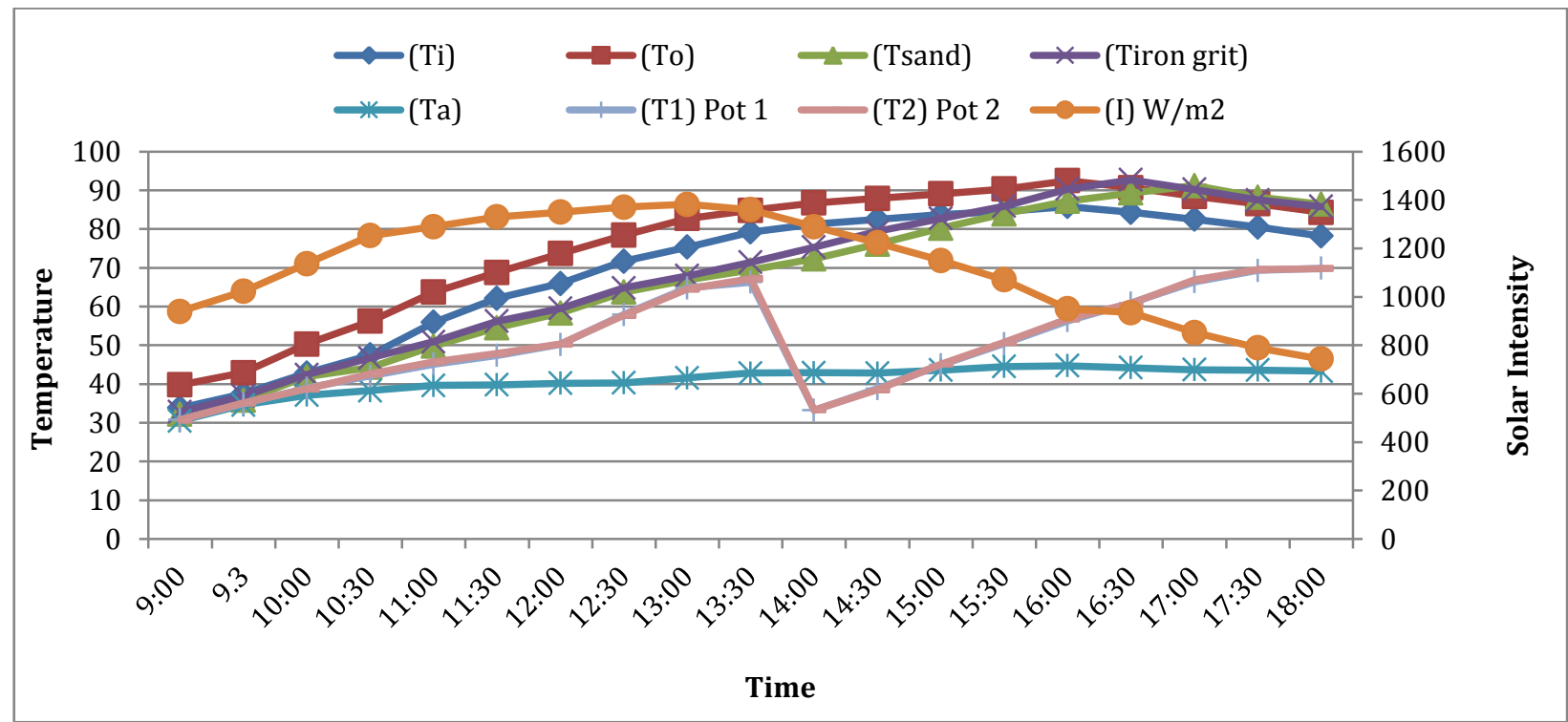

Fig. 5: Variation of temperature and Solar radiation intensity with time of Solar Cooker with (Rice + water and Pulses + Water) cooking load, 22 May 2015

\section{Analysis of Experimental Data}

In the experimental setup, temperature of iron grits, sand, ambient, water inlet and outlet temperature to the header and cooking medium temperature are measured with 'RTD PT 100' type thermocouples which are connected with digital temperature indicator having temperature range up to $600^{\circ} \mathrm{C}$ with a resolution of $1^{\circ} \mathrm{C}$. A solar power meter is also used to measure the intensity of solar radiations. The instrument used is of WACO 206 series having range up to $1999 \mathrm{~W} / \mathrm{m}^{2}$ with resolution of $0.1 \mathrm{~W} / \mathrm{m}^{2}$.Solar radiation intensity as well as various temperatures were measured from 9 A.M to 6 P.M. at regular interval 
of 30 minutes. Grits of iron as thermal heat storage medium is filled in the outer container and sand was kept inside the middle container. To check the feasibility and effectiveness several experiments were conducted in order to cook the food during morning and evening session.

At the start of experiment, TSU is placed on $0.30 \mathrm{~m}$ height above ETC which is aligned normal to the sun. ETC which is exposed to the sun concentrates solar radiations on the tubes which are placed on it. As a result of it; temperature of water flowing inside the tubes increases and due to thermosyphon phenomena water starts moving in upwards direction to the TSU through connecting pipes. Water inside copper tube transfer energy to the iron grits and then further to the sand. Temperature of iron and sand starts rising continuously. This increment in the temperature of iron and sand is termed as charging process. Intensity of solar radiations and various temperatures are measured at an interval of 30 minutes. TSU is designed for indoor afternoon and evening cooking. Temperature of iron grits and sand starts decreasing slowly which is termed as discharging process. This decrease in temperature leads to loss of heat from TSU. The cooking pot containing cooking medium (water, rice, pulses) is put in the cavity of TSU for cooking purpose which leads to fast decrease in temperature of sand and iron grits due to absorption of heat. This behavior of solar cooker is studied with and without cooking load.

\subsection{Energy stored by TSU}

This parameter is useful in calculating the amount of energy stored by TSU containing grits of iron and sand. The energy stored by TSU which is given by expression

$\mathrm{Q}_{\mathrm{TSU}}=\left[\left(\mathrm{m}_{\text {sand }} \cdot \mathrm{C}_{\text {sand }}\right) \cdot\left(\mathrm{T}_{\mathrm{m}}-\mathrm{T}_{\mathrm{i}}\right)+\left(\mathrm{m}_{\text {grit }}\right.\right.$. grit $\left.\left._{\text {gr }}\right) \cdot\left(\mathrm{T}_{\mathrm{m}}-\mathrm{T}_{\mathrm{i}}\right)\right]$

Where $\mathrm{m}_{\text {sand, }} \mathrm{C}_{\text {sand }}$ are the mass and specific heat of sand; $\mathrm{T}_{\mathrm{m}}$ and $\mathrm{T}_{\mathrm{i}}$ are the maximum and initial temperature, $m_{\text {grit }}, C_{\text {grit }}$ are the mass and specific heat of iron grits.

\subsection{Energy stored per unit time by TSU}

It is the ratio of energy stored by TSU to the time it takes during the charging process.

$Q_{W}=\frac{Q_{T S U}}{\tau}$

Where $\tau$ is time available during charging process.

\subsection{Heating Power}

It is the ratio of energy consumed by the cooking medium to the duration of cooking process.

$P_{H}=\frac{\left(m_{w} C_{w}\right) \cdot\left(T_{w 2}-T_{w 1}\right)}{\tau}$

Where $\mathrm{m}_{\mathrm{w}}, \mathrm{C}_{\mathrm{w}}, \mathrm{T}_{\mathrm{w} 1}, \mathrm{~T}_{\mathrm{w} 2}$ are mass, specific heat, initial and final temperature of cooking medium; $\tau$ is duration of cooking process.

\section{Results and Discussion}

The experimental setup is designed for cooking possible both for afternoon and evening session. The emphasis is laid on indoor cooking because it is unhygienic to cook in open and it is inconvenient for user to stand nearby the solar cooker in sunshine during cooking. The testing of experimental setup is done during sunny days of May 2015 at Mechanical Engineering department, Guru Jambheshwaruniversity of science and technology, Hisar. Design of experimental setup is based on the metrological conditions of the Hisar (29०09' N latitude and $75^{\circ} 42^{\prime} \mathrm{E}$ longitude). The cases which are considered are described in detail. During the experimental work, everyday evacuated tube solar collector was exposed to solar radiation in the early morning with the sun rise. In the experimental setup which included evacuated tube solar collector with the thermal storage unit, each time cooking experiments were conducted and testing was done.

Case 1: Testing the feasibility of solar cooker without cooking load: On 20 May 2015, the test of the solar cooker was done without any cooking load. On the first day, the solar cooker was exposed to solar radiation for charging at $9.00 \mathrm{am}$ and different measurements were taken up to $6 \mathrm{pm}$ at an interval of 30 minutes during charging and discharging process of the solar cooker. The temperature achieved by sand, iron grits, cooking pot and the variation in ambient and solar intensity with time are plotted in figure 3. During day time, the maximum solar intensity was recorded as $1370 \mathrm{~W} / \mathrm{m}^{2}$ at 1:00 pm and the ambient temperature was in the range of $30^{\circ} \mathrm{C}$ to $44.7^{\circ} \mathrm{C}$. From the figure it can be seen that, the maximum temperature achieved by sand and iron grits and cooking pot were $90.9^{\circ} \mathrm{C}$ and $91.5^{\circ} \mathrm{C}$ and $80.0^{\circ} \mathrm{C}$ respectively. Solar cooker was charged continuously till 5:00 pm and afterwards various temperatures were noted down during the discharging process of heat storage material. From the figure it can also be seen that the temperatures of heat storage materials decrease from $91.5^{\circ} \mathrm{C}$ to $81.7^{\circ} \mathrm{C}$ (iron grits) and $90.9^{\circ} \mathrm{C}$ to $78.3^{\circ} \mathrm{C}$ (sand) respectively in duration of 1 hour i.e. from 17:00hr to 18:00hr.

Case 2: Testing the feasibility of solar cooker water as a cooking load: On May 21, the solar cooker was loaded with 1 ltr water, $500 \mathrm{gm}$ water in each pot for cooking. During the day maximum solar intensity was 1378 $\mathrm{W} / \mathrm{m}^{2}$ at $13: 00 \mathrm{hr}$ respectively. From figure 4 , it can be observed that, the maximum temperature of cooking pot 1 and 2, sand and iron grits were $70.2^{\circ} \mathrm{C}, 71.1^{\circ} \mathrm{C}$, $88.3^{\circ} \mathrm{C}$ and $91.9^{\circ} \mathrm{C}$. Food was placed in the solar cooker at 9:00hr for morning session and again cooker is loaded with same load at 14:00hr for evening cooking session.

Case 3: Testing the feasibility of solar cooker with (water + rice) and (water + Pulses) as a cooking load: On May 22, the solar cooker was loaded with $150 \mathrm{gm}$ of 
rice in required proportion of water $(300 \mathrm{ml})$ and 150 gm pulse with $450 \mathrm{ml}$ water for cooking. During the day maximum solar intensity was $1382 \mathrm{~W} / \mathrm{m}^{2}$ at $13: 00 \mathrm{hr}$ respectively. From figure 5 , it can be observed that, the maximum temperature of cooking pot 1 and 2 , sand and iron grits were $70.1^{\circ} \mathrm{C}, 70.3^{\circ} \mathrm{C}, 91.2^{\circ} \mathrm{C}$ and $92.7^{\circ} \mathrm{C}$. Food was placed in the solar cooker at 9:00hr for morning session and again cooker was reload at 14:00hr for evening cooking session. The temperature in cooking pot is to be found $65^{\circ} \mathrm{C}$ at $19: 00 \mathrm{hr}$ which shows the capability of solar cooker to keep food warm till late night hour also.

In this section, the comparative analysis of various performance parameters are performed for the cases discussed above which is listed in Table 4. This comparison will helpful in comparing the performance of TSU for indoor morning and evening cooking session. From this comparison, it is concluded that TSU is having high heating power for evening cooking session. Solar cooker consists of many components which add up its cost. The use of solar cooker depends on its cost effectiveness and payback period. The cost estimation of solar cooker is listed in Table 5.Payback period is amount of time taken by solar cookers to recover its total cost. It is ratio of total cost of solar cooker to daily savings made by solar cooker. Solar cookers having large payback period for a given application are economically less feasible. We calculate payback period of solar cooker in terms of replacement of LPG and electricity.

\section{Case 1: Payback period of solar cooker in comparison of $L P G$}

Unsubsidized cost of one LPG cylinder is Rs. 1200 .

Average running period of $1 \mathrm{LPG}$ cylinder for a family of 4 members is 40 days.

Cost per day for cooking considering 1LPG cylinder $=1200 / 40=$ Rs. 30 .

Savings made on using solar cooker with TSU instead of LPG is Rs.30.

Payback period $=$ Total cost of solar cooker/savings per day $=8000 / 30=266.66$ days $=8.88$ months.

\section{Case 2: Payback period of solar cooker in comparison of electricity}

Electricity consumed for cooking food for a family of 4 members in a day $=5 \mathrm{kWh}$.

Cost of $1 \mathrm{kWh}$ of energy $=$ Rs. 7 .

Cost of electricity consumed by a family (4 members)

in a single day for cooking $=5^{\times} 7=$ Rs. 35 .

Payback period $=$ Total cost of solar cooker/savings per day $=8000 / 35=228.57$ days $=7.61$ months.

\section{Uncertainty Analysis}

The accuracy of measured data obtained through experimental study is very important which is dependent on the measuring instrument. Uncertainty analysis is performed to prove the extent of accuracy of experimental results. Uncertainty dependent on measuring instrument cannot be removed by number of measurements. The expression for uncertainty in the measured value by an instrument is given by Beckwith et al.

$\mu=\frac{a}{b_{\max }} \times 100$

where $a$ corresponds to the accuracy of the instrument and $b_{\max }$ is the maximum measured value of parameter by an instrument. The uncertainty analysis of measured values of parameters are performed and listed in Table 6.

\section{Conclusion}

The following conclusions can be drawn from the experimental study:

The solar cooker equipped with TSU can be able to perform indoor afternoon and evening cooking. Fully charged TSU is capable of cooking two batches of food. The heating power of solar cooker equipped with TSU is higher for evening cooking session as compared to morning cooking session. The payback period of solar cooker on replacement of LPG and electricity is 8.88 months and 7.61 months respectively.

Research should be carried out in developing highly efficient hybrid solar cooking unit so that it could cook food uninterruptedly during the complete diffusion of energy from the storage unit. These are the probable areas of interest on which work can be carried out in future for making the system more efficient, easy to handle, available at low cost and commercially viable for each and every household. In brief the upcoming era is of renewable energy resources and solar energy is one of them.

\section{References}

Saxena A., Varun, Pandey S.P., Srivastav G. (2011), A thermodynamic review on solar box type cookers, Renewable and Sustainable Energy Reviews: 15, 33013318.

Ramadan, M. R. I., S. Aboul-Enein, and A. A. El-Sebaii (1988), A model of an improved low cost-indoor-solar-cooker in Tanta. Solar \& wind technology 5, no. 4: 387-393.

Al-Saad, M. A., and B. A. Jubran(1991), The performance of a low cost clay solar cooker. Renewable energy 1, no. 5: 617 621.

Domanski, R., A. A. El-Sebaii, and M. Jaworski (1995), Cooking during off-sunshine hours using PCMs as storage media. Energy 20, no. 7: 607-616.

Buddhi, D., \&Sahoo, L. K. (1995), Solar cooker with latent heat storage: design and experimental testing. Energy Conversion and Management, 38(5), 493-498.

Funk, P. A., and D. L. Larson (1998), Parametric model of solar cooker performance. Solar Energy 62, no. 1: 63-68

Gaur, A., Singh, O. P., Singh, S. K., \&Pandey, G. N. (1999), Performance study of solar cooker with modified utensil Renewable Energy, 18(1), 121-129. 
Sharma, S. D., D. Buddhi, R. L. Sawhney, and Atul Sharma. (2000), Design, development and performance evaluation of a latent heat storage unit for evening cooking in a solar cooker. Energy Conversion and Management 41, no. 14: 1497-150

Buddhi, D., Sharma, S. D., \& Sharma (2003), A. Thermal performance evaluation of a latent heat storage unit for late evening cooking in a solar cooker having three reflectors. Energy Conversion and Management, 44(6): 809-817.

Schwarzer, K., \& Da Silva, M. E. V. (2003), Solar cooking system with or without heat storage for families and institutions. Solar Energy, 75(1) : 35-41.

Kumar, Subodh. Thermal performance study of box type solar cooker from heating characteristic curves. Energy conversion and management 45, no. 1 (2004): 127-139.

Harmim, A., Belhamel, M., Boukar, M., \& Amar, M. Experimental investigation of a box-type solar cooker with a finned absorber plate. Energy,35 (9), (2010): 3799-38

Harmim, A., Merzouk, M., Boukar, M., \& Amar, M. Mathematical modeling of a box-type solar cooker employing an asymmetric compound parabolic concentrator. Solar Energy, 86(6), (2012): 1673-1682

Sethi, V. P., D. S. Pal, and K. Sumathy. Performance evaluation and solar radiation capture of optimally inclined box type solar cooker with parallelepiped cooking vessel design. Energy Conversion and Management 81 (2014): 231-241.

Sharma, Atul, C. R. Chen, V. V. S. Murty, and AnantShukla. Solar cooker with latent heat storage systems: A review. Renewable and sustainable energy reviews 13 , no. 6 (2009): 1599-160
R.M. Murthusivagami, R. Velraj and R. Sethumadhvan, Solar cookers with and without thermal storage - A review, Renewable Sustainable Energy Rev. 14 (2010) 691-7

Saxena, Abhishek, S. P. Pandey, and G. Srivastav.A thermodynamic review on solar box type cookers Renewable and Sustainable Energy Reviews 15, no. 6 (2011): 3301-3318

Prasanna, U. R., and L. Umanand. Modeling and design of a solar thermal system for hybrid cooking application.Applied Energy 88, no. 5 (2011): 1740-1755

Panwar, N. L., S. C. Kaushik, and Surendra Kothari. State of the art of solar cooking: an overview. Renewable and Sustainable Energy Reviews 16, no. 6 (2012): 3776-3785.

Mussard, Maxime, and Ole JørgenNydal. Charging of a heat storage coupled with a low-cost small-scale solar parabolic trough for cooking purposes. Solar Energy 95 (2013): 144154

Mussard, Maxime, AlexandreGueno, and Ole JørgenNydal. Experimental study of solar cooking using heat storage in comparison with direct heating.Solar Energy 98 (2013): 375-3

Saini Gagandeep, Singh Hardeep, SainiKaramjeet, YadavAvadesh. Experimental investigation of solar cooker during sunshine and off- sunshine hours using thermal energy storage unit based on parabolic trough collector. International journal of ambient energy (2015).

Beckwith T.G., Marangoni R.D., Lienhard J.H., Mechanical Instruments, Addison-Wesley Publishing company, New York:45-112 (1990). 